\title{
The Media Arcane
}

\author{
Beyes, Timon; Pias, Claus
}

Document Version

Final published version

Published in:

Grey Room

DOI:

10.1162/grey_a_00271

Publication date:

2019

License

Unspecified

Citation for published version (APA):

Beyes, T., \& Pias, C. (2019). The Media Arcane. Grey Room, 75(75), 84-105.

https://doi.org/10.1162/grey_a_00271

Link to publication in CBS Research Portal

\section{General rights}

Copyright and moral rights for the publications made accessible in the public portal are retained by the authors and/or other copyright owners and it is a condition of accessing publications that users recognise and abide by the legal requirements associated with these rights.

Take down policy

If you believe that this document breaches copyright please contact us (research.lib@cbs.dk) providing details, and we will remove access to the work immediately and investigate your claim.

Download date: 26. Apr. 2023
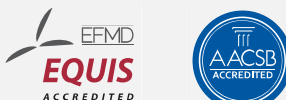


\section{The Media Arcane}

Timon Beyes and Claus Pias

Journal article (Publishers version*)

\section{Please cite this article as:}

Beyes, T., \& Pias, C. (2019). The Media Arcane. Grey Room, 75(75), 84-105.

https://doi.org/10.1162/grey_a_00271

DOl: https://doi.org/10.1162/grey_a_00271

\section{(1) २०२० The MII Press.}

The MIT Press allows authors to share their articles for noncommercial purposes in institutional repositories such as CBS Research Portal (https://www.mitpressjournals.org/for authors).

Uploaded to CBS Research Portal: September २०२० 


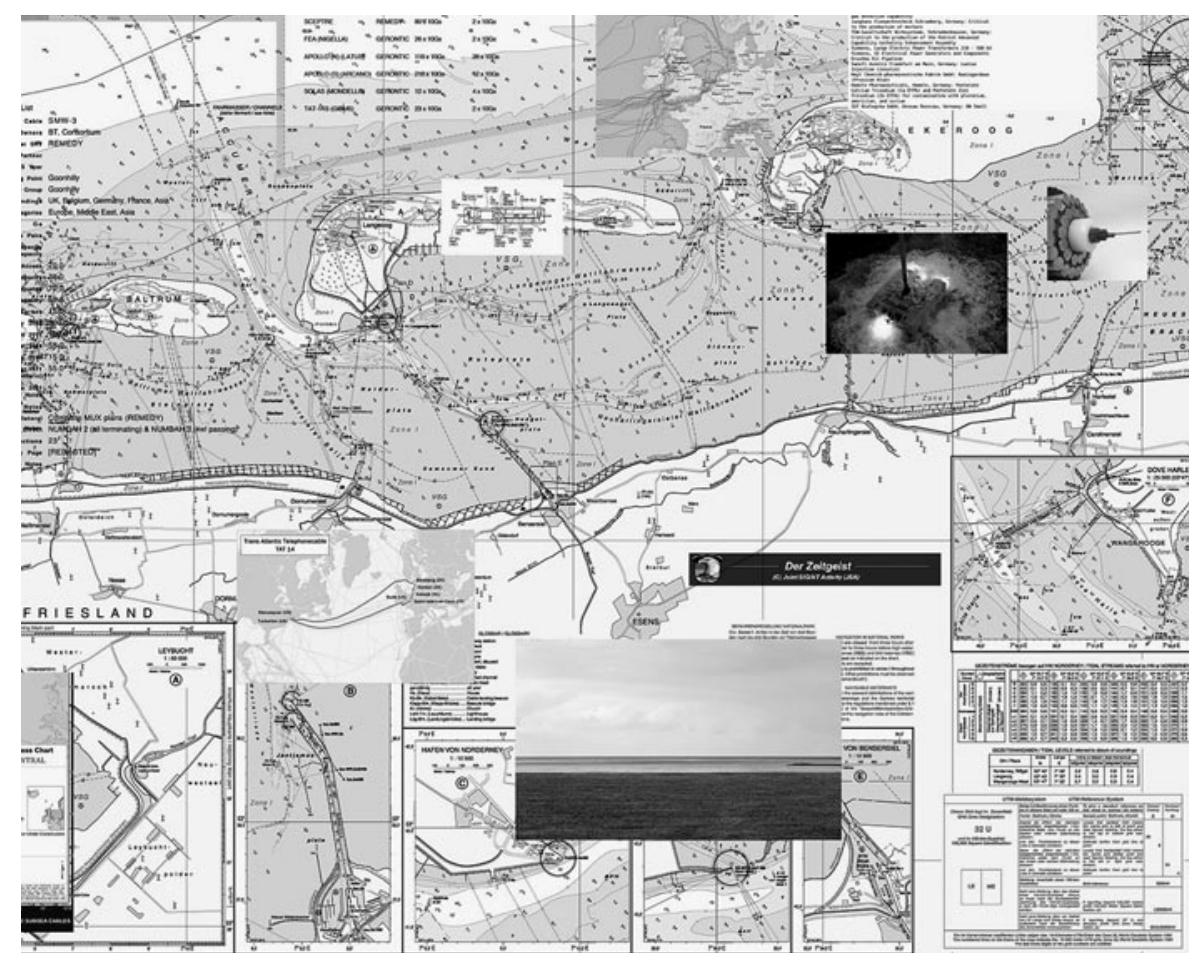

Trevor Paglen. NSA-Tapped Fiber 


\section{The Media Arcane}

\section{TIMON BEYES AND CLAUS PIAS}

I.

"U," the protagonist of Tom McCarthy's most recent novel, Satin Island, is an anthropologist with a Ph.D. dissertation on club culture. Plucked "from the dying branches of academia," he now works for "the Company," a Londonbased consultancy. ${ }^{1}$ At times, its offices have bandwidth problems. In one of these episodes, $\mathrm{U}$ experiences an epiphany:

There was too much information, I guess, shuttling through the servers, down the cables, through the air. . . . The buffering didn't bother me, though; I'd spend long stretches staring at the little spinning circle on my screen, losing myself in it. Behind it, I pictured hordes of bits and bytes and megabytes, all beavering away to get the requisite data to me; behind them, I pictured a giant über-server, housed somewhere in Finland or Nevada or Uzbekistan: stacks of memory banks, satellite dishes sprouting all around them, pumping out information non-stop, more of it than any single person would need in their lifetime, pumping it all my way in an endless, unconditional and grace-conferring act of generosity. Datum est: it is given. It was this gift, I told myself, this bottomless and inexhaustible current of giving, that made the circle spin: the data itself, its pure, unfiltered content as it rushed into my system, which, in turn, whirred into streamlined action as it started to reorganize it into legible form. The thought was almost sublimely reassuring. ${ }^{2}$

McCarthy here stages a kind of organizational theology in which the invisible hand of automated data generation and circulation is presented as destiny beyond human comprehension. ${ }^{3}$ So-called big data is "given" and "unconditional," "endless" and "inexhaustible," a "grace-conferring” gift. Perceived as a reassuring data sublime, it is fundamentally secret, of unfathomable intelligence, and perhaps unknowable. It becomes a vision of the contemporary arcane: a media-technologically induced mysterium of secret information whose circulation is connected to the infrastructures of server farms, satellite dishes, and computer hardware.

The novel dramatizes similar incidents and patterns of secrecy and intransparency as governing forces of today's organized world. U is asked to participate in a "supra-governmental, supra-national, supra-everything" project. ${ }^{4}$ Other than it having to do with networked infrastructures, neither 
U nor his colleagues have much of a clue about what they are working on. The project is a "black box," amorphous, shape-shifting, and opaque; itself a kind of medium, "it has to be conceived of as in a perpetual state of passage, not arrival—not at, but in between." 5 Toward the end of the novel, Madison, U's girlfriend or occasional partner, recounts her experience at the antiglobalization protests in Genoa, Italy. After being beaten up by the police, she was brought to a hidden site where she was connected to a strange predigital media device used for experiments indecipherable to her and never explained—a lesson in state secrecy no less than in state violence.

II.

U's (and Madison's) predicament is shaped by technologically mediated forms and episodes of secrecy, intransparency, and not-knowing. As such, it seems at odds with the notions of transparency, access, and participation that have dominated the recent decades of the media-technological imagination. As Manfred Schneider points out, during the last twenty years or so, a "messianic potential" has consolidated in the ideal and ideology of transparency. ${ }^{6}$ And if transparency represents one of today's most prominent concepts, then digitalization can be said to designate the media-technological condition of its ubiquity. This corresponds approximately to the span of time in which forms of digital world-making have prevailed, forms whose technological basis has come to characterize the systems and processes of communication, affect, perception, and the bestowal of meaning. ${ }^{7}$ This development has made clear that we have to speak of digital cultures in the plural, if only because the heterogeneity of this sociotechnical arrangement seems to correspond to various forms of world-making that have arisen in tandem with the digital media environment that now pervades our lifeworld.

In opposition to the messianism of the transparent and secret-free spheres of, say, politics and business-a messianism that derives its energy from the Internet's fiber-optic cables and the omnipresence of intelligent artifacts that can, in part, communicate with one another without the intervention of human subjects-stands the nightmare of a "transparency society" in which the exposed lives of individuals become "big data" in the hands of Internet companies and government intelligence agencies. While remaining intransparent themselves, both the behemoths of platform capitalism and state bureaucracy collect and evaluate the traces left behind by digital users, ushering in the age of "surveillance capitalism" and the "security-entertainment

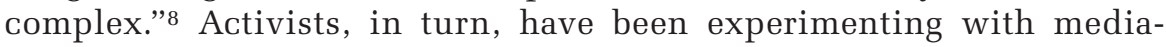
technically enabled tactics of intransparency and secrecy in order to make it possible for user-based representations of identity to escape into anonymity 
or into subject positions that are fluctuating and temporary, updating an imaginary of playacting, concealment, and dissimulation as tactical forms of an activist politics of secrecy. ${ }^{9}$ The Edward Snowden-National Security Agency affair, moreover, confirmed Schneider's laconic dictum, which McCarthy's U would doubtless also confirm: "In the here and now, there is no transparency." 10

As Wendy Chun has remarked in the pages of this journal, the conflation of computing power with transparency is contradicted by what computation does; namely, it generates rather than represents texts and images, and the corresponding abstraction of data is based on the hiding of information. Chun therefore suggests we regard the infatuation with transparency as a "compensatory gesture": "As our machines increasingly read and write without us, as our machines become more and more unreadable, . . . we the so-called users are offered more to see, more to read. The computer-that most nonvisual and nontransparent device-has paradoxically fostered 'visual culture' and 'transparency."'11 The ploy or "trick" of the digital era is then this: to claim that it offers transparency, an infrastructure of open exchange and deliberation, while all the while feeding off of and producing secrecy. The illusion of transparency is itself exacerbated by contemporary media-technological constellations, or what we term "the media arcane."

Rather than mourning qualities of transparency, participation, and public deliberation presumably lost, it behooves us to bring the very concepts of secrecy and the arcane, so long sidelined by morally charged discourse in favor of digital transparency, to the forefront of our attention. Our contribution to this debate is devoted to conceptualizing digital cultures not-or at least not primarily - in terms of the problematic nature and potential of transparency (or of related concepts such as participation and the public sphere) but rather to follow $\mathrm{U}$ in thinking about them in terms of the secret, in terms of fundamental intransparency, and in terms of the arcane. Our first step will thus be to (re)call to mind the general social form-at least beyond its commonly understood ethical dubiousness - of the secret and its functionality. Drawing on the related work of Georg Simmel, this will allow us to shed a more sobering light on the interplay of secrecy and its betrayal. We then venture an experimental-historical approach-a thought experiment-that will enable us to reexamine, in greater detail and with reference to premodern types of secrets, the present state of digital cultures on the basis of their temporal structures. This is followed by a tentative discussion of the social, political, and epistemological layers of a "broad present" that needs to be thought of in terms of secrecy and the arcane. We then conclude by considering the implications for what has been called "German" media thinking. ${ }^{12}$ 
III.

Simmel's meandering essay on "the sociology of secrecy and secret societies" marks an invaluable point of departure for reflecting on the social form of the secret. Simmel considered secrecy-independent of its contents and the attributions of value associated with it—to be a universal sociological form that is necessary for differentiating social relations. ${ }^{13}$ Secrecy's "attractions" are enabled by such differentiation as much as they intensify it. ${ }^{14}$ Believing in the "messianic potential" of transparency directed against the form of the secret is sociologically dubious, since a world without secrecy is either unthinkable or, if thinkable, then only as a dystopian vision.

Secrecy in this sense-i.e., which is effective through negative or positive means of concealment-is one of the greatest accomplishments of humanity. In contrast with the juvenile condition in which every mental picture is at once revealed, every undertaking is open to everyone's view, secrecy procures enormous extension of life, because with publicity many sorts of purposes could never arrive at realization. ${ }^{15}$

Hence, each relation between persons-and between (wo)man and machine, as well as machine and machine — can be characterized and analyzed according to the ratio of secrecy it manifests. And every sociotechnical relation is surrounded by, or shrouded in, a more or less opaque fog of secrecy. Simmel uses the term energies to discuss secrecy's affective qualities, its mix of retentive and revelatory forces. ${ }^{16}$ And U's experience of a kind of constitutive organizational intransparency would not have surprised Simmel, for whom the form of the organization constituted the "peculiarly discreet sociological formation."17

To write the history of secrecy is thus one way of tracing the development of society: a sequence of revealed things that have become secret and of secret things that have been revealed. This yields a sort of zero-sum game of incoming and outgoing contents that are worthy of confidentiality, of secrecy and revelation, covertness and betrayal, with secrecy functioning as an operator of social evolution. Moreover, such thinking would caution against assumptions that the current colonization of societal spheres by the logic of secrecy is a particularly new phenomenon. ${ }^{18}$ Rather, the logic of secrecy has been constitutive of modern life and social organization as well as its technologies.

IV.

In light of today's digital cultures, it is reasonable to question Simmel's speculation that, as "the affairs of people at large become more and more public, those of individuals [become] more and more secret." ${ }^{19}$ Yet his suggestion 
that "what was formerly secret ceases to require such protection and proclaims itself," while "what was formerly public passes under the protection of secrecy," has proven to be prescient. ${ }^{20}$ Is the self-exposure of digital users on the Internet not indicative of the porous nature of the distinction between the public and the private, and does the discovery of secret masses of data by WikiLeaks and Snowden not prove the existence of an enormous apparatus of secrecy?

Thus, again, Simmel's basic idea-that the secret deserves to be taken seriously as a fundamental category of cultural analysis-still seems fruitful. The notion and the phenomena of secrecy are particularly pertinent examples of how so-called new media resuscitate and perhaps reconfigure what are basic and enduring concerns and troubles of sociotechnical relating. ${ }^{21}$ What this calls for, then, is a historical investigation of various forms of secrecy in order to gain insight into its present-day varieties. ${ }^{22}$ From a historical perspective, moreover, the significance of such modes of secrecy can be shown to lie not only in the capacity to not reveal but, correspondingly, in the weakness "relative to the temptation to betrayal," as Simmel writes. ${ }^{23}$ This kind of inquiry also extends to the systematically prior and historically premodern question of what is able to be betrayed and what-in light of this ability or inability to be an object of betrayal—constitutes the significance and the logic of the secret in various cultures and at various times. ${ }^{24}$

We thus propose, as a thought experiment, to think about digital cultures not only through the notion of the secret but beyond any concept of modernity that posits digital cultures as themselves the final product of, or as having brought an end to, that modernity. ${ }^{25}$ Many of today's passionate debates illustrate this issue by means of a latent anachronism that finds expression in the use of established concepts such as transparency, the public sphere, and participation. ${ }^{26}$ To intensify and take this anachronism further: How would digital cultures be understood if we set aside modern concepts (and ever-derivative postmodern concepts) and instead examined digital cultures through the strangeness of premodern concepts wherein the secret possesses an altogether different and, at least for our purposes, potentially fruitful historical semantics?

\section{V.}

Until the seventeenth century, cosmology drew a line at an essentially secretive realm. The line thus demarcated a fundamental unknown in the form of natural secrets. In a comparable manner, "high" matters of state were regarded, on the basis of their nature, as secretive. The resolutions, decisions, and deeds enacted by the lords of wisdom were thought to possess a secret 
and essentially unfathomable intelligence, without which the stability of the state could not be preserved. The resolutions, decisions, and deeds themselves were clear for all to see, but the reasons behind them could not be betrayed and thus could not be discussed. In cosmological terms, they were as incommunicable as all the great matters of nature. Therefore, they represented not only wisdom, the arbitrary nature of which "has to be protected from triviality and thus kept secret," but also structurally unbetrayable secrets. ${ }^{27}$

Modern science was the first to raise an objection to such secrets; it did so mainly with the goals of gaining knowledge about nature with natural means and of removing all authority from the "cosmic-religious stop sign." 28 The idea that things are unknowable because God is unknowable gave way to an openness to epistemological progress-to a belief in the human ability to decipher natural secrets under the new media conditions of the printing press. While this increase in knowledge also enhanced the sensation of the world's unfamiliarity, to forge ahead in the pursuit of learning no longer seemed meaningless. In terms of Niklas Luhmann's sociological systems theory, that is, the de-paradoxification of natural secrets and the temporalization of their complexity no longer seemed meaningless.

This development was more complex and long-winded than suggested by this kind of media-historical construction of epochs and ruptures through key technologies (Leitmedien). According to Ivan Illich, the emergence of a scientific practice of reading and writing the "bookish text" predates the invention of the printing press. ${ }^{29}$ William Eamon shows how the disengagement from esotericism in natural philosophy-that is, the transition from (fundamentally unknowable) arcana naturae to epistemic secreta known or temporarily unknowable for historically contingent reasons-extended into the eighteenth century. ${ }^{30}$ Consider, too, that influential accounts of the printing press as change agent or of printed books as "immutable mobiles" tend to produce a retrospective illusion of "fixity," not taking into account how such books' formats and reproduction techniques varied greatly and how principles of courtly recognition bestowed the kind of authority on printed texts that legitimized them as "knowledge" in the first place. ${ }^{31}$

As crude as our periodization appears in the light of these studies, the fact remains that the treatment of secrecy before the "saddle time" of about 1800 was more differentiated than it is today (or in Simmel's exposition). This is because premodernity was familiar with various types of secrets-such as the arcana cordis, the arcana dei, the arcana naturae, and the arcana imperiieach of which obeyed different concepts, methods, and rationalities. The primary distinction to keep in mind here is that between the mysterium (something nonknowable and thus nonbetrayable) and the secretum (something 
concealed that can be made intelligible and thus be betrayed). The arcana imperii incorporates both aspects: the mysterium of the ruler's wisdom and caprice as the center of an unbetrayable reasoning and, at the same time, a bustling multiplicity of minor or major secreta that are the objects of betrayal and of efforts to keep them secret from all sorts of "intelligence" (literally, that is, from possible forms of insight). The eighteenth century unmasked and "secularized" the arcana imperii and, above all, excluded the concept of the mysterium: "The printing press ... had trivialized them [the arcana imperii] into mere book titles for case studies and textbooks. And the modern historian then retrospectively read the literature of arcana imperii as though its topic were simply a dubious means of justifying the raison d'état." ${ }^{32}$ From that point on, the mysterium was consigned to "faith," while secreta were treated as something that had to be brought to light.

VI.

In this sense, the debates held today among politicians and in newspapers and blogs concerning data protection and privacy rights operate with-at least from our perspective-a reductive conception of secrets; namely, with those that can be betrayed. As soon as the shift is made into this modern category, a secret can either be betrayed or not be betrayed, revealed or kept confidential, and is always suspected of serving particular interests. Without this hegemony of a particular type of secret, the idea of transparency associated with the "bourgeois public sphere" could never have been formulated. It is the type of secret that can and must be revealed, and it simultaneously creates a situation in which it is unclear whether the state should fear civil society or vice versa. With this newfound suspicion of sovereignty, along with an active interest in unmasking arcana, the type of secret that is unbetrayable seems either to have been lost or relocated to another realm. ${ }^{33}$

As Reinhard Koselleck shows, the unbetrayable secret has been sublimated into a new temporal order. ${ }^{34}$ To some extent, modernity has transferred the unbetrayable secret of sovereignty onto time itself. The future has become the secret that cannot be betrayed. Moreover, modernity has firmly associated the question of the future with the notion of participation and the public sphere. Both are embedded in a context of secrecy and transparency that are oriented toward the future. Otherwise participation-according to our modern understanding of it-would be meaningless, because it takes place between what is and what ought to be: between how the world is and how it (otherwise) could be. The eighteenth century thus invented not only a new form of historicity but a new form of history itself, and it came to treat the present as the decisive place between the "space of experience" and the 
“horizon of expectation,” as the venue of an essentially open future. ${ }^{35}$

With digital cultures, a new temporal order has been established: a "chronotope" that is distinct from the temporal order that was established between the years 1780 and 1830 and subsequently defined "Western" thinking. We believe the beginnings of this change can be traced to the rise of modern cybernetics after the year 1945. As Norbert Wiener suspected as early as 1948, the advent of digital computers-along with concepts such as feedback, self-regulating systems, and prediction-initiated a fundamental rearrangement of temporal structures. ${ }^{36}$

The attempt to align the "physical functioning of the living individual" with that of "newer communication machines" (Wiener's terms) initiated a set of problems that can be likened to lifting a full glass of water to one's mouth. Whoever (or whatever) might be doing the lifting is no longer the Cartesian active subject with its sequence of willful acts and consequences but is instead caught up in a continuous sequence of "real-time" data and calculations in an effort to ensure that the future of the glass will have been to reach the mouth without spilling. Such an act requires target-oriented adjustments of motion, and for these it is decisive at which distances comparisons are made between present and future values and how drastically the motion needs to be corrected. It is decisive-in short-to know how the "constraints" of the system have to be measured so that it will function. Feedback that is too drastic or frequent will lead to "clumsy behavior." The drink will spill precisely because of the motion that has been undertaken to prevent spillage, and the whole process will enter a state of oscillation that can otherwise be observed only in experimental conditions with subjects suffering from so-called intention tremors. Cybernetics had a keen interest in such disruptive phenomena because it understood its first order of business to be their prevention. Thus, the discipline's focus was less on the consequences of action than on the intervals of "real time" and on the knowledge of what sort of interventions might ensure that a given system continues to perform satisfactorily.

Such "target-oriented" actions become more and more complicated if the target in question does not stand still. A cat that wants to catch a fleeing mouse does not jump to where the mouse presently is but rather to where it will next be; it jumps toward the future of the mouse. Or, to do justice to the military context of cybernetics: Whoever wants to shoot down an airplane must be able to read the evasive tactics of the enemy and interpret these data in order to strike the airplane in its future location. The magic word for all of this is prediction, and the ability to predict things was believed to improve with increased amounts of data. Prediction lies at the heart of cybernetics, 
which was gradually "demilitarized" in the 1950s with its examples of cats and full glasses and thus became an acceptable model for the humanities and social sciences. ${ }^{37}$

The future task of cybernetics would thus be to install such machines à gouverner in the realm of politics and to model them according to stateof-the-art technical systems. "Nondeterministic teleology" became a magic expression that led some to believe they could define goals, introduce a system, and then walk away from it all with the expectation that their desired results would necessarily come to be. The path in between led through a black box whose internal processes were unknown and-above all—did not have to be known. Thus, though cybernetics itself had caused them to disappear, human beings could nevertheless slip back in through the humanistic back door-namely, as those who autonomously set the goals and then left the task of accomplishing them to machines (in their inscrutable manner). This, however, essentially closed off the openness of the future.

Above all, the lasting legacy of cybernetics is precisely this phantasmatic excess of faith in gaining control over the future by yielding, in a targeted manner, control over some of its aspects. For the open future of nuclear war and totalitarianism, overpopulation, pollution, and the depletion of resources was not supposed to come about. A sort of homeodynamics delegated to machines thus seemed to offer the best chance of avoiding such outcomes. As Jay Forrester remarked in the early 1970s, all "intuition, judgement, and argument" would have to be removed from the political sphere because they are not "reliable guides to the consequences of an intervention into system behavior"- behavior that could be computed but exceeded human understanding. ${ }^{38}$ Stability, that is, demands the eschewal of an open future, which can be achieved only by employing a black box of incomprehensible means.

With the digitalization of further aspects of our lifeworld and with the countless number of apparatuses that can communicate with one another independently and can - the largest and smallest alike—control one another mutually and provide feedback to one another, these particularly cybernetictemporal relations have become more or less absolute. Arguably, they engender an order of time in which modern historicity collapses. One could perhaps call this an "absolutism of the present" (to adapt a phrase from Robert Musil) or, to borrow Hans-Ulrich Gumbrecht's terms, refer to it as a "broad present.". 39 The cybernetic chronotope of digital cultures thus raises yet again, as a topic of discussion, the question of historical temporalities.

This diagnosis is not new. A quarter-century ago, for instance, Vilém Flusser offered a similar interpretation. ${ }^{40}$ If, according to Flusser, a bond exists between cybernetic machines that interconnect by means of feedback, 
that behave adaptively, that process interferences independently, and that allow, by means of what today is called "big data," the data traces of subjects to be conflated with the prediction of forms of subjectivation-then the relation between what is and what ought to be collapses and thus, with it, the modern concept of an open future. Like other thinkers before and after him, Flusser refers to this condition as "post-history.” For logical reasons, according to his diagnosis, there can no longer be any conventionally understood arguments, critiques, or politics within this new temporal order. Participation, as Flusser radically infers, is thus "nonsense." 41 In contrast to this bleak outlook, we propose to think about today's digital cultures precisely not in terms of modern concepts but, at least tentatively, in terms of premodern concepts. For if the modern temporal order has become problematic or has even collapsed entirely, the challenge would then consist in conceptualizing digital cultures not with the categories of transparency, participation, and the public sphere but in terms of a fundamental intransparency - that is, in terms of the arcane.

VII.

If the origin of this new temporal order can be ascribed to the cybernetic concepts of feedback, self-regulating systems, prediction, and digital computers, then we can state at the same time that digital and networked media are the agent of this different construction of time, which one might call the "chronotope of prediction." The everyday examples of how this media environment affects and affords social, or rather sociotechnical, organization are countless: entire industries have since arisen that are concerned with predicting such things as what type of music we like to listen to, which television series we like to watch, who we should really be friends with, or how we can best avoid traffic on our way to work. With greater and greater masses of data, it is becoming increasingly probable to predict even the seemingly unpredictable twists and turns of the subject—something like anticipating the evasive, zigzag maneuvers of an enemy airplane. To escape from ourselves is no longer possible; rather, we are incessantly confronted with ourselves and with our own surprising predictability. As George Dyson says, "Facebook defines who we are, Amazon defines what we want, and Google defines what we think." 42

Being deprived of an open future in such ways-this blending of the "space of experience" and the "horizon of expectation" in favor of a mediatechnical feedback loop between the past and the future-can perhaps be better understood with premodern concepts of time. ${ }^{43}$ And it correspondingly requires us to think of these processes of ordering experience and con- 
duct in terms of secrecy and the arcane. McCarthy's Satin Island is a particularly shrewd, fictionalized reflection on the intransparency of an organized life that is affected by the arcane generation, circulation, and exploitation of data through automated algorithms. While the programmed codes of such hidden algorithms point to a betrayable secret (after all, Google is "zealously guarding its secret sauce"), its computing power is unfathomable and incomprehensible to human consciousness and thus takes on qualities of a mysterium that, in agreeable moments, might lead to experiences of a kind of blissful data sublime. ${ }^{44}$ Yet this kind of opacity is at the heart of what Shoshana Zuboff terms "surveillance capitalism" (Zuboff also focuses on Google as a currently dominant "media a priori"). ${ }^{45}$ Data or "surveillance assets" are extracted from user populations, then used for pattern recognition and predictive analytics as well as the modulation of moods to achieve what Zuboff calls "anticipatory conformity." 46 This is "a new kind of sovereign power," for which secrecy is constitutive and which in this regard seems closer to the arcana imperii of premodern times than an enlightened or even participatory form of late capitalism. ${ }^{47}$ In similar terms, and as John Lanchester points out, it does not make much sense to see Facebook as an organization that seeks to enable and foster the open and free exchange of information and knowledge. Rather, Facebook profitably trades on a logic of secrecy that has turned it into "the biggest surveillance-based enterprise in the history of mankind." 48

Consequently, the thesis that premodern concepts allow for a different and perhaps more adequate reflection of social organization in digital cultures could also be advanced in light of additional concepts and phenomena. For example, the "like" culture of so-called social media has less to do with modern participation than it does with premodern rituals. "Likes" seem to resemble more the états, cortes, or parliaments that were common from the late Middle Ages up into the eighteenth century. As rituals, they have a standardized and almost algorithmic form that guarantees their "correct" performance. They require a particular public sphere that confirms their social order without demanding any consensus regarding their significance. Rituals are performative-that is, productive instead of representational—and their performance is based on a purely external execution through which they reinforce the ongoing existence of institutions. ${ }^{49}$ Such forms of "participation," to which modernity had put an end, were rituals of consensus and not negotiations of dissent. ${ }^{50}$ In fact, modernity disavowed just such rituals as the opposite of the political. They operated according to a sort of logic that has nothing to do with a participatory public sphere based on arguments and transparency. They were necessary and performative forms of participation 


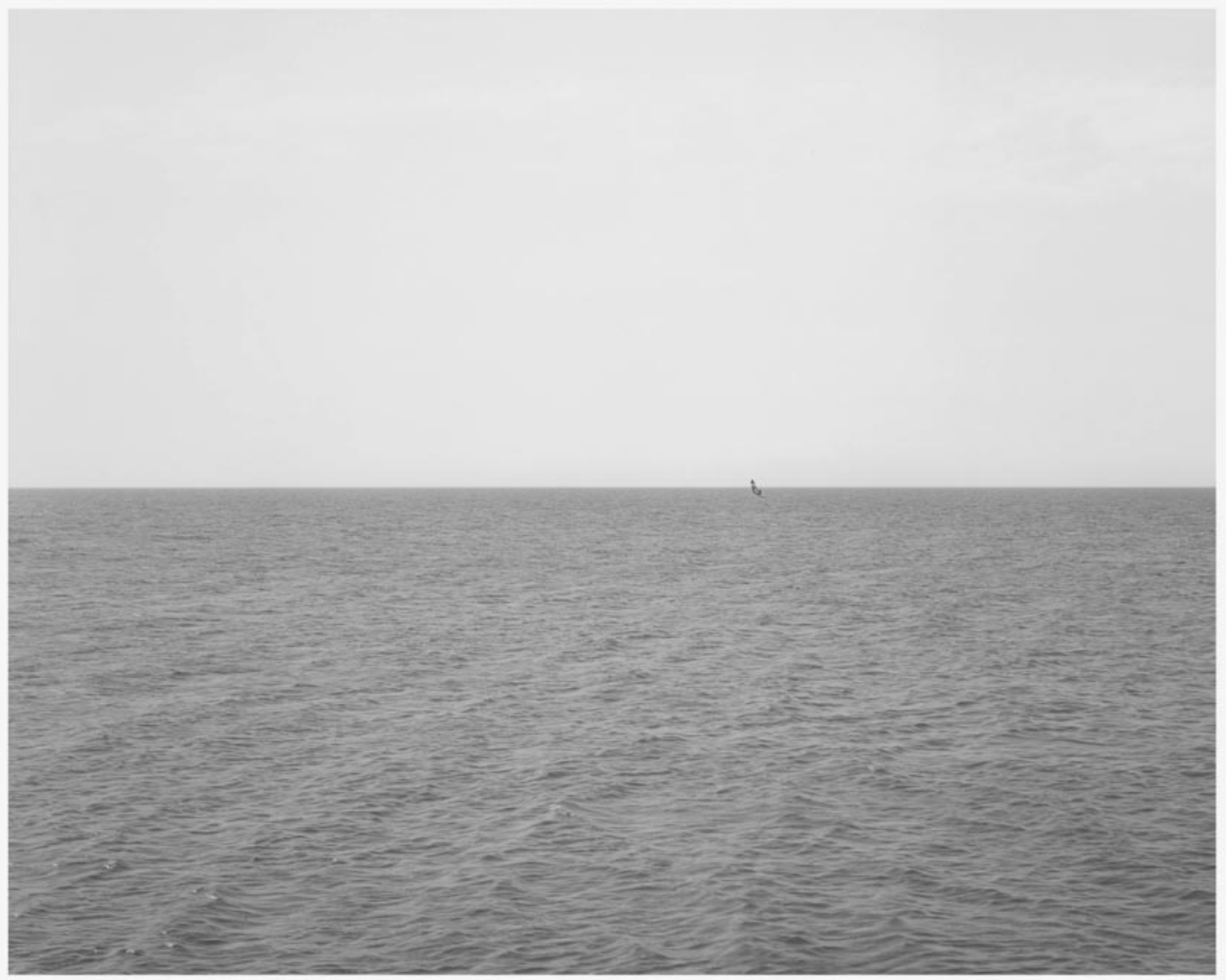

Trevor Paglen. NSA-Tapped Fiber Optic Cable Landing Site, Norden, Germany, 2015. Courtesy the artist; Metro Pictures, New York;

Altman Siegel, San Francisco. 
within a non-future-oriented temporal order because they lacked the concept of decision-making itself.

VIII.

If modernity turned the unbetrayable secrets of the mysterium into betrayable secreta, and if digital cultures again reconfigure this relation, then the political arcana imperii of digital cultures' broad present become a matter of concern. According to Koselleck, whose argument echoes Simmel's insight into secrecy as the operator of social evolution, a dialectic of secrecy and enlightenment that can be traced back to the absolute state now shapes the emergence and development of the modern state. ${ }^{51}$ As Howard Caygill points out, the largely moral outcry over, and critique of, the recent revelations of global surveillance programs (and the secret collusions of Internet providers with state agencies) might therefore miss out on the political stakes of the arcana imperii in times of the ubiquity of digital technology. ${ }^{52}$

The "secret chambers" of the political arcanum are constitutive for the modern state and its transformations. ${ }^{53}$ Rather than conceiving of secrecy as a complementary counterpart of transparency, as Eva Horn does, Caygill argues that "[t]he state, while appearing to be related to the political, obeys, above all, the arcanum of secrecy-its very arcanum is secrecy." 54 The "ethos of the secret" thus pervades the state apparatus. This is precisely what Madison's encounter with the state's machinery of secrets in Satin Island asks us to reflect on. Just as the state possesses a monopoly on the legitimate use of violence, it also possesses, and is even defined by, "a monopoly in the legitimate use of the instruments of secrecy." 55 It is thus "constitutionally arcane" and will employ everything at its disposal to defend its claim to secrecy. ${ }^{56}$ As Caygill sums up, "[p]erhaps the state is there to ensure that politics doesn't happen." 57

In this sense, the thesis of a contemporary colonization of "our political and legal systems" by "the logic of secrecy" appears to be ahistorical: the logic of secrecy is at the root of the political system. ${ }^{58}$ And yet, the politicaleconomic expansion of secrecy, which enables and goes hand in hand with the rise of surveillance capitalism, has been widely diagnosed. ${ }^{59}$ Profitable technological development in conjunction with state interests provokes or drives such constellations. As Schmitt speculated in 1923, "It would seem as if this kind of secret would be particularly understandable for technicaleconomic thought and from here might represent the beginning of a new uncontrollable power." ${ }^{60}$ For Schmitt, then, a kind of postpolitical arcanum involving close relations between corporate power and government was already on the horizon in the early twentieth century. ${ }^{61}$ Perhaps this "new 
uncontrollable power" has now reconfigured the arcanum of the state in an era of ubiquitous and pervasive media technologies. Nigel Thrift suggests calling this technologically reconfigured organizational nexus between economic and political actors the "security-entertainment complex."62 Echoing Flusser's (and Zuboff's) notion of automated, adaptive feedback loops and their predictive capacities, this security-entertainment nexus relies on hidden machines à gouverner of data extraction and information targeting and is manifested by "an era of permanent and pervasive war and permanent and pervasive entertainment, both sharing the linked values of paranoiac vigilance and the correct identification of the potential of each moment."63 Reflecting on the politics of secrecy thus not only seeks to avoid the hysteria that marks the unveiling and the betrayal of the secretum by showing that certain things have always been removed from public oversight or debate. ${ }^{64}$ It also needs to acknowledge and think a more expansive apparatus-and chronotope-of prediction and surveillance whose mechanisms seem beyond, or unperturbed by, individual acts of disclosure and betrayal.

IX.

A look at climatology is especially striking in this context, for hardly any other domain of knowledge is epistemologically so dependent on the historical state of hardware and software: on the observable leaps in quality enabled by sheer computing power but also on a history of software in whose millions of lines of poorly documented or undocumented code have been sedimented archaeological layers of scientific thinking that, for good reason, cannot be touched or rewritten but only expanded and globally standardized and certified. That which is processed in the supercomputers of such a global research alliance can simply no longer be made transparent-not even to the scientists involved. It follows that the habitual routines of critique are at a loss to address the kind of alternative worlds (and not merely prognoses) that result, as well as what might guide our behavior and self-perception under these conditions.

The common reflex of citing the "constructedness" of knowledge achieves little in this regard, for it does not absolve one from acting in the face of scenarios that are conscious of their own constructivism. And the falsifiability of classical scientific ethics (not merely for reasons of capacity but for systematic reasons as well) is not practicable in this case because it is impossible to experiment with the climate as an object of science. Following Bruno Latour, one could ask who is really bothered by not fully understanding the technical world, given that what counts are less "matters of fact" than "matters of concern"-or, that which we affectively believe should concern us and 
challenge the moral interpretability of the world and our grounds for action. Going a step further, one could respond to Latour's question-" [W] hat does it mean when this lack of sure ground is taken away from us?"-with the following answer: If the codes (to stick with our example) are no longer a secretum but are openly available for everyone to see, and if they have nevertheless become unintelligible and undebatable in their history, quantity, and complexity, then they have in fact become a mysterium, and their consequences and decisions have to be accepted as an act of faith. ${ }^{65}$

Accordingly, some climate scientists have begun to consider a new cosmology in order to justify our future activity on a global level. ${ }^{66}$ Should this demand be extended to all possible fields in which the degree of networking, computer power, and software development has achieved a measure of complexity at which understanding and comprehension are impossible-fields that, nevertheless, create a feedback loop between the present and the future? Consider the numerous questions about the ethical and juridical attribution of decisions and their agential consequences and thus about the preservation of a Cartesian model that is transferred to autonomous decisions by increasingly intransparent machines. This conundrum is reflected by recent efforts to establish the field of "artificial neuroscience," which is supposed to reconstruct and visualize the processes of decision making at work in the neural networks of artificial intelligence. ${ }^{67}$ The problem of algorithmic prediction and execution has already been extensively discussed in the context of high-frequency trading in the financial markets (e.g., in the aftermath of the "flash crash" of 2010), and it has recently gained public attention in the context of "autonomous car fatalities" related to "Franken-algorithms." 68

If the epistemological becomes entwined around a center of nonknowledge and nonunderstanding, a modern concept of transparent knowledge reaches its limits, as does the idea of participation by means of voicing one's opinion about "the matter at hand." And even this can be expressed, with recourse to thinking about the secret, in premodern terms: The idea of a computer-simulated climate cosmology and the legitimation strategy for a field called "artificial neuroscience" structurally correspond to the premodern political register of sovereignty. Climate research and the rapidly growing field of artificial intelligence become, in this sense, prototypes of a new, datadriven and increasingly automated science royale. In the place once occupied by the wisdom (or caprice) of the ruler-a place protected by a metaphysical limit to knowledge-there is now the sovereignty of data processing, which has drawn a new line to demarcate that which is constitutively evasive by being secretive according to its "nature." Only, it is no longer nature and no 
longer cosmology but technology. Previously, and with respect to sovereign rule, this was referred to as the "arcane."

$\mathbf{X}$.

These examples, taken from the realms of social organization, politics, and epistemology, and to which many more could be added, raise the question of how much one can and must know about the "apparatuses" (in Flusser's sense of the term) that create the particular temporality of digital cultures. They provoke reflections on which secrets these apparatuses might possess that perhaps ought to be made transparent, and they raise the paradoxical question of which secrets they are hiding that are unbetrayable or should perhaps remain protected. To this extent, our attempt at interpretation will stand or fall depending on the issue of the "understanding" of digital media. And this "media-understanding," as Friedrich Kittler surmised some thirty years ago, is perhaps a melancholy enterprise. His pronouncement that media "determine our situation" was made at a moment when, in light of the emergence of digital cultures, the limitations or even impossibility of our being able to understand them was already beginning to loom. In Kittler's words, "The general digitization ... erases the differences among individual media. ... . [A] total media link on a digital base will erase the very concept of medium. Instead of wiring people and technologies, absolute knowledge will run as an endless loop.”69

As if embodying Kittler's prognosis, Satin Island's corporate anthropologist fails in writing the "Great Report," the task his enigmatic boss bestows on him. Not only is the "absolute knowledge" unavailable to the anthropological gaze; it is itself doing the anthropologist's work. The "Great Report" is continuously written by and for software:

Write Everything Down, said Malinowski. But the thing is, now, it is all written down. . . Not by a person, nor even by some nefarious cabal, but simply by a neutral and indifferent binary system that had given rise to itself, moved by itself and would perpetuate itself: some autoalphaing and auto-omegating script. ... And that we, far from being its authors, or its operators, or even its slaves (for slaves are agents who can harbor hopes, however faint, that one day a Moses or a Spartacus will set them free), were no more than actions and commands within its key-chains. ${ }^{70}$

And yet, Satin Island is a report of sorts: a description of, and reflection on, the contemporary media arcane. As such, it offers a possible response to the plea for new types of representation and even for a new poetics of rendering 
intelligible network-based governance and control. ${ }^{71}$ These efforts can thus be understood as attempts to oppose the intransparency, unrepresentability, and incommensurability of algorithmic ordering with a different "understanding" of digital media and to respond to the absolutism of the present with new images and forms of thinking that go beyond the mere betrayal of secreta and do greater justice to the mysterium of a media-technically conditioned arcanum. Especially at stake here is the related issue of action and the basis for action if this is to take place in a chronotope that, to rephrase Flusser, is no longer determined by transparency, capable of deliberative reasoning, or open to the future. The discourse about transparency, which is always making or reflecting an ethical claim, has reached the limits of a secret that is challenging us to conceptualize an ethics without transparency and a future without the modern understanding of participation and the public sphere. ${ }^{72}$

So-called German media theory, to which this journal devoted an entire issue in 2007, has always been marked by an antihermeneutic tradition: Its aim has been to understand not meaning itself but its presemantic technological conditions. For this reason, the question of what "media" are in a substantial sense, has always been irrelevant. ${ }^{73}$ Particularly in the Kittlerian tradition, this has not excluded (but rather included) the melancholy undertaking of trying to comprehend media on a technical level and describe them in terms of their functional operations-and to do so in light of the meaningful effects they exert over our thinking, feelings, and behavior.

With digital media, yet another reductionist principle has been followed: Even though the speed, abundance, and complexity of algorithmically processed data were already incommensurable, the hope remained that it might still be possible, "in principle," to understand "the computer" (as a medium)—namely, as a "switching principle” (to borrow one of Kittler's notorious expressions) of all the social, cultural, and collectively meaningful epiphenomena that derive from it. This situation has changed, however, now that digital cultures have become self-evident and mundane. What forms of description remain to be discovered or rediscovered that would allow us to reflect on the chronotope of prediction and the ubiquitous "black-boxing" of its mechanisms? Under such conditions of prediction and black-boxing, how can we then think without claiming to understand ${ }^{74}$ We suggest a reconsideration of the general form of the secret and, particularly, of its premodern varieties and corresponding temporalities so as to gain a vocabulary for thinking about digital cultures as a technologically conditioned nexus of secrets. 


\section{Notes}

1. Tom McCarthy, Satin Island (London: Jonathan Cape, 2015), 24.

2. McCarthy, 67-68; emphasis in original.

3. Even the company's physical structures, its central London premises, are "datafied," made inscrutable, and call for a quasi-theological language: "Separated from each other by floor-to-ceiling glass partitions on which lower-case letters in the Company's own, distinctive font were stenciled, these compartments ran on one into the next, creating an expansive vista in which sketches, diagrams and other such configurations of precious data, lying face-up on curved tabletops, pinned to walls or drawn on whiteboards or, occasionally (and this made the data seem all the more valuable, fragile even), on the glass itself, seemed to dialogue with one another in a rich and esoteric language, the scene conveying (deliberately, of course) the impression that this was not only a place of business but, beyond that, a hermetic zone, a zone of alchemy, a crucible in which whole worlds were in the mix." McCarthy, 14; emphasis in original.

4. McCarthy, 110.

5. McCarthy, 60, 74; emphasis in original.

6. Manfred Schneider, Transparenztraum: Literatur, Politik, Medien und das Unmögliche (Berlin: Matthes und Seitz, 2013), 13.

7. Ted Striphas, "Algorithmic Culture," European Journal of Cultural Studies 18, no. 4-5 (August-October 2015): 395-412; Felix Stalder, The Digital Condition, trans. Valentine A. Pakis (Cambridge, UK: Polity, 2017); Andreas Bernard, The Triumph of Profiling: The Self in Digital Cultures (London: Polity Press, forthcoming); and Timon Beyes, Jörg Metelmann, and Claus Pias, eds., Nach der Revolution: Ein Brevier digitaler Kulturen (Hamburg: Edition Speersort, 2017).

8. On the notion of a "transparency society," see Byung-Chul Han, The Transparency Society, trans. Erik Butler (Stanford, CA: Stanford University Press, 2015). On "surveillance capitalism," see Shoshana Zuboff, "Big Other: Surveillance Capitalism and the Prospects of an Information Civilization," Journal of Information Technology 30, no. 1 (March 2015): 75-89. For the "security-entertainment complex," see Nigel Thrift, "Lifeworld Inc—and What to Do About It," Environment and Planning D: Society and Space 29, no. 1 (February 2011): 5-26.

9. Eva Horn, "Actors/Agents: Bertolt Brecht and the Politics of Secrecy," Grey Room, no. 24 (Summer 2006): 38-55. The group known as "Anonymous" has thus far been the most captivating example of this. See Gabriella Coleman, Hacker, Hoaxer, Whistleblower, Spy: The Many Faces of Anonymous (London: Verso, 2015).

10. Schneider, 14.

11. Wendy Chun, "On Software, or the Persistence of Visual Knowledge," Grey Room, no. 18 (Winter 2004): 27.

12. Eva Horn, "Editor's Introduction: There Are No Media," Grey Room, no. 29 (Fall 2007): 6-13.

13. Georg Simmel, "The Sociology of Secrecy and of Secret Societies," American Journal of Sociology 11, no. 4 (January 1906): 441-98.

14. Simmel, 465.

15. Simmel, 462.

16. Simmel, 466.

17. Simmel, 449; emphasis in original. 
18. See, for example, Frank Pasquale, The Black Box Society: The Secret Algorithms That Control Money and Information (Cambridge, MA: Harvard University Press, 2015).

19. Simmel, 468.

20. Simmel, 463 .

21. John Durham Peters, The Marvelous Clouds: Toward a Philosophy of Elemental Media (Chicago: University of Chicago Press, 2015).

22. Aleida Assmann and Jan Assmann, Schleier und Schwelle, 3 vols. (Munich: Fink, 19971999).

23. Simmel, 466.

24. Eva Horn, "Logics of Political Secrecy," Theory, Culture and Society 28, no. 7-8 (December 2011): 103-22.

25. Jean François Lyotard, The Postmodern Condition: A Report on Knowledge, trans. Geoff Bennington and Brian Massumi (Manchester: Manchester University Press, 1984).

26. Inge Baxmann, Timon Beyes, and Claus Pias, eds. Social Media—New Masses (Zurich: Diaphanes, 2016).

27. Niklas Luhmann and Peter Fuchs, Reden und Schweigen (Frankfurt: Suhrkamp, 1989), 116.

28. Luhmann and Fuchs, 104.

29. Ivan Illich, In the Vineyard of the Text: A Commentary to Hugh's Didascalicon (Chicago: University of Chicago Press, 1993).

30. William Eamon, Science and the Secrets of Nature: Books of Secrets in Medieval and Early Modern Culture (Princeton, NJ: Princeton University Press, 1994). In this context, "secret books" were part of a blooming "how-to revolution" in the sixteenth and seventeenth century and did not just disappear through the "triumph of modern science." Tapping into the semantics of arcana naturae for promotional purposes, such secret books dealt less with secrets than with "maker's knowledge" and practical rules and can be seen as early profiteers from a transformation of secrets and experiments into commodities (10).

31. On the printing press, see Elizabeth Eisenstein, The Printing Press as an Agent of Change: Communications and Cultural Transformations in Early Modern Europe (Cambridge, UK: Cambridge University Press, 1979). On books as "immutable mobiles," see Bruno Latour, "Drawing Things Together," in Representation in Scientific Practice, ed. Michael Lynch and Steve Woolgar (Cambridge, MA: MIT Press, 1990), 19-68. On courtly recognition, see Adrian Johns, The Nature of the Book: Print and Knowledge in the Making (Chicago: University of Chicago Press, 1998).

32. Luhmann and Fuchs, 118.

33. As unbetrayable secrets, mysteria continue to exist in different forms; for instance, as (the invisible hand of) "market mechanisms," "the unconscious," or even as "life."

34. Reinhard Koselleck, Futures Past: On the Semantics of Historical Time, trans. Keith Tribe (New York: Columbia University Press, 2004).

35. Koselleck, Futures Past, 255-75.

36. Norbert Wiener, Cybernetics: Or Control and Communication in the Animal and the Machine, 2nd ed. (Cambridge, MA: MIT Press, 1961), 60-94.

37. See Norbert Wiener, The Human Use of Human Beings: Cybernetics and Society (New York: Houghton Mifflin, 1950).

38. Jay Forrester, World Dynamics, 2nd ed. (Cambridge, MA: Wright-Allen, 1973), 97. 
39. Hans-Ulrich Gumbrecht, Our Broad Present: Time and Contemporary Culture (New York: Columbia University Press, 2014).

40. Vilém Flusser, Gestures (1991), trans. Nancy Ann Roth (Minneapolis: University of Minnesota Press, 2014).

41. Flusser, 17-18. Flusser explains that figures such as functionaries, terrorists, technocrats, and environmentalists are social types specific to a present in which participation has become logically impossible.

42. George Dyson, Turing's Cathedral: The Origins of the Digital Universe (New York: Pantheon, 2012), 308.

43. See also Christian Geulen's historicization of Koselleck's concept: “As in early modernity, experience and expectation are today inclined once again to belong to a common spacebut this time with expectation in the lead." Christian Geulen, "Plädoyer für eine Geschichte der Grundbegriffe des 20. Jahrhunderts,” Zeithistorische Forschungen 7, no. 1 (2010): 83.

44. Pasquale, 13.

45. Zuboff. The phrase "media a priori" is from Peters, 9.

46. Zuboff, 82.

47. Zuboff, 86.

48. John Lanchester, "You Are the Product," London Review of Books 39, no. 16 (2017): 8. Or consider the financial markets and their organizations, whose employees, let alone clients, cannot follow and "understand" what the programmed, automated algorithms do. Or note how the U.S. administration "embraced the expansion of executive secrecy, with far-reaching (and occasionally surreal) results. By 2010, leading intelligence agency experts could not even estimate the overall costs of the U.S. antiterrorism effort; nor could they map the extent of the surveillance apparatus they had built.” Pasquale, 13.

49. For a comprehensive discussion of this phenomenon, see Barbara Stolberg-Rillinger, Rituale (Frankfurt: Campus, 2013).

50. André Krischer, "Das Problem des Entscheidens in systematischer und historischer Perspektive," in Herstellung und Darstellung von Entscheidungen: Verfahren, Verwalten und Verhandeln in der Vormoderne, ed. André Krischer and Barbara Stollberg-Rilinger (Berlin: Duncker and Humblot, 2010), 35-64.

51. Reinhard Koselleck, Critique and Crisis: Enlightenment and the Pathogenesis of Modern Society (Cambridge, MA: MIT Press, 1988).

52. Howard Caygill, "Arcanum: The Secret Life of State and Civil Society," in The Public Sphere from outside the West, ed. Divya Dwivedi and Sanil V (London: Bloomsbury, 2015), 21-40.

53. See the thesis developed by Carl Schmitt toward the end of his Römischer Katholizismus und politische Form (1923), 5th ed. (Stuttgart: Klett-Cotta, 2008).

54. Caygill, 27; emphasis in original. Compare Horn, "Logics of Political Secrecy."

55. Caygill, 27.

56. Caygill, 37. Regarding bureaucratic domination, Max Weber, Simmel's contemporary and friend, argued that keeping operations secret would not only be in the "material nature" of certain administrative fields but concealing its knowledge and actions would be a primary interest of every bureaucracy: "The concept of the 'official secret' is the specific invention of bureaucracy, and nothing is so fanatically defended by the bureaucracy as this attitude.” Max Weber, “The Power Position of Bureaucracy,” in From Max Weber: Essays in Sociology (1921), 
trans. H.H. Gerth and C. Wright Mills (New York: Oxford University Press, 1946), 233.

57. Caygill, 33.

58. Pasquale, 2 .

59. See Peter Galison, "Secrecy in Three Acts," Social Research 77, no. 3 (Fall 2010): 94174; and Jörn Knobloch, "Demokratie und Geheimnis," in Staatsgeheimnisse: Arkanpolitik im Wandel der Zeiten, ed. Rüdiger Voigt (Wiesbaden: Springer, 2017), 205-24.

60. Schmitt, 58.

61. Less radically than Schmitt, yet clearly informed by this kind of thinking, the sociologist Helmut Schelsky diagnosed in 1965 that technological-scientific decisions would elude democratic procedures: "In comparison with regarding the state as a universal technical body, the classical conception of democracy as community whose politics depend on the will of the people seems more and more like an illusion. Without being anti-democratic, the 'technical state' deprives democracy of its substance. Technical-scientific decisions cannot be subject to any democratic effort to build consensus; in this way they would be ineffective. If the political decisions of the state are made according to scientifically controlled objective legalities [Sachgesetzlichkeiten], then the government is an organ for administrating objective necessities [Sachnotwendigkeiten] and the parliament is an organ for controlling objective correctness [sachliche Richtigkeit]." Helmut Schelsky, "Der Mensch in der wissenschaftlichen Zivilisation," in Auf der Suche nach Wirklichkeit: Gesammelte Aufsätze (Düsseldorf: Eugen Diederichs, 1965), 439-80. Schelsky was probably still of the belief that objective legalities are "objectively" tested and that science is at least "falsifiable." Our argument here is that, in digital cultures, the secret resides to some extent "in the matter itself" (in der Sache selbst), be it in the weak version of the secretum (such as algorithms that are company secrets) or as a mysterium (as in the case of artificial intelligence and climate research).

62. The notion of an "organizational nexus" or "organizational complex" is taken from Reinhold Martin's study connecting the emerging cybernetic regime of control and the figure of the "organization man" to postwar corporate architecture and its technological infrastructure. See Reinhold Martin, The Organizational Complex: Architecture, Media, and Corporate Space (Cambridge, MA: MIT Press, 2003).

63. Thrift, 11.

64. Horn, "Logics of Political Secrecy."

65. Bruno Latour, "Why Has Critique Run Out of Steam? From Matters of Fact to Matters of Concern," Critical Inquiry 30, no. 2 (Winter 2004): 227.

66. See, for instance, the eminent climatologist Wolfgang Lucht, quoted in "Excerpt from the Panel Ground/Groundlessness: Claus Pias, Wolfgang Lucht, Anke Eckardt," in Anke Eckardt, Sonic Spaces: Ground-Wall-Verticality (Berlin: Revolver, 2014), 24-33.

67. Cade Metz, "Google Researchers Are Learning How Machines Learn,” New York Times, 16 March 2018, https://www.nytimes.com/2018/03/06/technology/google-artificialintelligence.html.

68. On the "flash crash," see Neil Johnson et al., "Abrupt Rise of New Machine Ecology beyond Human Response Time," Scientific Reports 3, no. 02627 (2013), https://www.nature.com/ articles/srep02627. Franken-algorithms is a neologism coined by Andrew Smith in an article on "the deadly consequences of unpredictable code." Thanks to self-generating algorithms, there is now a "code universe" that can no longer be fully understood. "Basically," Smith argues, "we need a new science." Andrew Smith, "Franken-Algorithms: The Deadly 
Consequences of Unpredictable Code," The Guardian, 13 August 2018, https://www. theguardian.com/technology/2018/aug/29/coding-algorithms-frankenalgos-program-danger.

69. Friedrich Kittler, Gramophone, Film, Typewriter, trans. Geoffrey Winthrop-Young and Michael Wutz (Stanford, CA: Stanford University Press, 1999), 1-2.

70. McCarthy, 123; emphasis in original.

71. Alexander Galloway, “Are Some Things Unrepresentable?” Theory, Culture and Society 28, no. 7-8 (December 2011): 85-102.

72. Latour, "Why Has Critique Run Out of Steam?”; and Heinz von Foerster, Understanding Understanding: Essays on Cybernetics and Cognition (New York: Springer, 2003).

73. Horn, "Editor's Introduction: There Are No Media."

74. James Bridle, New Dark Age: Technology and the End of the Future (London: Verso, 2018), 6. 